\title{
Post-ERCP complications, risk factors and management of complications
}

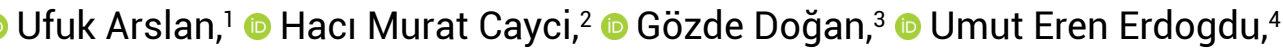 \\ ๑ Ali Tardu, ${ }^{5} \odot$ Direnç Yiğit, ${ }^{1} \odot$ Yurdakul Deniz Firat, ${ }^{4} \odot$ Müfit Şansal' \\ 'Department of Gastroenterological Surgery, Bursa State Hospital, Bursa, Turkey \\ ${ }^{2}$ Department of Gastroenterological Surgery, Private Medical Office, Bursa, Turkey \\ ${ }^{3}$ Department of General Surgery, Doruk Hospital, Bursa, Turkey \\ ${ }^{4}$ Department of General Surgery, Bursa Yüksek intisas Training and Research Hospital, Bursa, Turkey \\ ${ }^{5}$ Department of Gastroenterological Surgery, Irmed Hospital, Tekirdağ, Turkey
}

\begin{abstract}
Introduction: Endoscopic retrograde cholangiopancreatography (ERCP) is an interventional procedure used for the diagnosis and treatment of hepatopancreaticobiliary system diseases. The aim of this study is to evaluate post-ERCP complications, risk factors, and management of complications of ERCP procedures performed in the endoscopy unit of our hospital.

Materials and Methods: The study retrospectively reviewed 765 patients' data of ERCP performed by the same endoscopist for the diagnosis and treatment of hepatopancreaticobiliary diseases at a single center between April 2019 and February 2021. Interventional procedures were reviewed in terms of ERCP indications, procedure-related complications, risk factors for complications, and management of the complications.

Results: A total of 765 procedures were carried out. The successful cannulation rate was $91.9 \%$. The most common indicators for the ERCP procedure were choledocholithiasis (43.6\%), high levels of cholestasis biomarkers/intra-extrahepatic bile duct dilatation (19\%) ve removal of bile duct stents (12.5\%). The most common risk factors were; female gender $(60.9 \%)$ and younger age $(42.3 \%)$ for post-ERCP pancreatitis, pre-cut (10.9\%) and anticoagulant therapy (7.5\%) for bleeding, papillary abnormalities (22.4\%) for perforation, and older age (42.8\%) for cholangitis. The most common complications were hyperamylasemia and pancreatitis (17.2\%), bleeding (2\%), cholangitis (1.83), and perforation (0.65\%). Mortality occurred in $0.26 \%$ of patients due to post-ERCP cholangitis.

Conclusion: Understanding the risk factors and early diagnosis and treatment of complications are the ways to reduce morbidity and mortality in the management of post-ERCP complications.
\end{abstract}

Keywords: Complication; early diagnosis; endoscopic retrograde cholangiopancreatography; hepatopancreaticobiliary system; risk factors.

\section{Introduction}

Endoscopic retrograde cholangiopancreatography (ERCP) is a widely used, effective, and safe endoscopic procedure for the diagnosis and treatment of biliary and pancreatic system diseases. ${ }^{[1]}$ Post-ERCP complications are 20 times more common and four times more severe than complica- 
tions due to standart endoscopic procedures. ${ }^{[2]}$ In general, post-ERCP complication rate is $10 \%$, while the mortality rate is $0.33-1 \%{ }^{[3-5]}$

Complications during ERCP can occur due to many factors such as selection of patients, experience of endoscopist, and anatomical variations. ${ }^{[3,6]}$ Patient-related risk factors (e.g. anticoagulant therapy, cirrhosis, end-stage renal failure, advanced age, etc.) need to be evaluated before the procedure in order to take precautions to reduce complications. $^{[3]}$

The aim of our study is to review complications due to ERCP procedures which are performed at the endoscopy unit of our hospital, risk factors for ERCP procedure, and management of post-ERCP complications.

\section{Materials and Methods}

Data of 765 patients who have undergone ERCP procedure for diagnosis or treatment at the endoscopy unit of our hospital between April 2019 and February 2021 were collected and studied retrospectively. Procedures were evaluated in terms of patients' demographic informations, indications for the procedure, complications of procedure, risk factors for complications, and the management of these complications. All procedures were performed by the same endoscopist. All patients submitted informed consent. Our study was conducted in accordance with the World Medical Association's Declaration of Helsinki. Ethics committee approval was obtained from Bursa State Hospital for the study. (Number: 2021-7/17) (Date: 21/04/2021).

Anticoagulant therapies were ceased at least 5 days before procedure and patients were administered low molecular weight heparin instead. Each patient was evaluated by an anesthesiologist before procedure. Sedoanalgesia was provided by an anesthesiologist. Patients were monitored for heart rate, oxygen saturation, and blood pressure. Patients were administered 2-4 lt/min oxygen with nasal cannula during the procedure. Topical lidocaine $10 \%$ was used to numb the patients' throats. Patients who had high intestinal motility were administered hyoscine N-butylbromide (Buscopan ${ }^{\circledR}$ ) in order to ease the cannulation. Patients were in prone position during the procedure. After cannulation of choledoch, Urografin ${ }^{\circledR}$ diluted 1:3 with saline solution was used for bile duct imaging. After the procedure, patients were kept under observation for $1 \mathrm{~h}$ in case of any complication. Patients without any adverse clinical situation after the ERCP procedure were discharged home with physical examinations and laboratory tests scheduled for the next day. Patients who had symptoms such as stomachache, nausea, vomiting, and fever were hospitalized.

In the present study, Shapiro-Wilk test was used to assess whether the age variable followed a normal distribution. According to the Shapiro Wilk test, age variable was expressed with the mean, minimum and maximum values, while the categorical variables were reported with frequency and related percentage values. SPSS (IBM Corp. Released 2012. IBM SPSS Statistics for Windows. Version 20.0. Armonk. NY: IBM Corp.) software was used for statistical analysis. $\mathrm{P}<5 \%$ was considered statistically significant.

\section{Results}

The total number of procedures was 765 . Succesful cannulation rate was $91.9 \%$. Of the patients, $60.9 \%$ were female. The mean age was 58.6 (18-88) years. The most common indications for ERCP were choledocholithiazis (43.6\%), elevated cholestasis biomarker levels and dilated intra-extrahepatic bile ducts (19\%), and stent extraction (12.5\%) (Table 1). Other ERCP indications included malignant diseases, biliary pancreatitis, bile fistula, cholangitis, and parasitic diseases of bile ducts.

The most common post-ERCP complications were hyperamylasemia and pancreatitis (17.2\%), bleeding (2\%), cholangitis (1.83\%), and perforation (0.65\%) (Table 2). In addition, one patient had basket impaction, one patient had esophageal laceration, and one patient had pneumothorax. Two patients $(0.26 \%)$ died due to post-ERCP cholangitis.

\section{Table 1. ERCP indications}

\begin{tabular}{lcc} 
Indications & n & $\%$ \\
\hline Common bile duct stones & 334 & 43.6 \\
Elevated cholestatic enzymes / & 146 & 19 \\
and intrahepatic-extrahepatic & & \\
bile duct dilatation & & \\
Pancreatic - bile duct malignancies & 73 & 9.5 \\
Biliary pancreatitis & 67 & 8.7 \\
Bile duct injury / biliary fistula / & 42 & 5.4 \\
cholangitis (Emergency ERCP) & & \\
Stent removal & 96 & 12.5 \\
Parasitic diseases of the biliary tract & 7 & 0.91 \\
\hline
\end{tabular}

ERCP. Endoscopic retrograde cholangiopancreatography. 
Table 2. ERCP complications

\begin{tabular}{lcc} 
Complications & $\mathbf{n}$ & $\%$ \\
\hline Elevated serum amylase & 132 & 17.2 \\
$\quad$ Less than twice & 72 & 9.4 \\
$\quad$ More than twice & 60 & 7.8 \\
Pancreatitis requiring hospitalization & 28 & 3.6 \\
Perforation & 5 & 0.65 \\
$\quad$ Requiring surgery & 2 & 0.26 \\
$\quad$ Not requiring surgery & 3 & 0.39 \\
Bleeding & 16 & 2 \\
$\quad$ Endoscopic treatment & 3 & 0.39 \\
Conservative treatment & 13 & 1.6 \\
Cholangitis & 14 & 1.83 \\
Pneumothorax & 1 & 0.13 \\
Basket impaction & 1 & 0.13 \\
Esophageal laceration & 1 & 0.13 \\
Mortality & 2 & 0.26 \\
\hline
\end{tabular}

ERCP. Endoscopic retrograde cholangiopancreatography.

Table 3. Risk factors for post-ERCP pancreatitis

\begin{tabular}{lcc} 
& $\mathbf{n}$ & $\%$ \\
\hline Patient-related factors & & \\
Abnormal papilla & 172 & 22.4 \\
Oddi dysfunction & 38 & 4.9 \\
Female gender & 466 & 60.9 \\
Young age (<50 years) & 324 & 42.3 \\
Previous pancreatitis & 23 & 3 \\
Non-dilated bile duct & 58 & 7.5 \\
Normal serum bilirubin & 73 & 9.5 \\
End-stage renal failure & 5 & 0.65 \\
Procedure-related factors & & \\
Pancreatic cannulation & 68 & 8.8 \\
Pancreatic injection & 7 & 0.9 \\
Pancreatic sphincterotomy & 34 & 4.4 \\
Pre-cut & 84 & 10.9 \\
Biliary balloon sphincter dilatation & 12 & 1.5 \\
\hline ERCP. Endoscopic retrograde cholangiopancreatography. & \\
\hline
\end{tabular}

The most common patient-related risk factors for post-ER$\mathrm{CP}$ pancreatitis (PEP) were female gender (60.9\%), younger age (42.3\%), and papillary abnormalities (22.4\%), while most common procedure-related risk factors were pre-cut (10.9\%) and pancreatic cannulation (8.8\%) (Table 3). The most common risk factors: for bleeding were pre-cut
Table 4. Risk factors for other complications

\begin{tabular}{lcc} 
& $\mathbf{n}$ & $\%$ \\
\hline Risk factors for bleeding & & \\
Use of anticoagulants & 58 & 7.5 \\
Low platelet count & 6 & 0.78 \\
Cirrhosis & 3 & 0.39 \\
End-stage renal failure & 5 & 0.65 \\
Intraprocedural bleeding & 16 & 2 \\
Low level of endoscopist's experience & & \\
Pre-cut & 84 & 10.9 \\
Risk factors for cholangitis & & \\
Incomplete biliary dilatation & 18 & 2.3 \\
Hilar obstruction & 12 & 1.5 \\
Previous ERCP & 82 & 10.7 \\
>60 years of age & 328 & 42.8 \\
Risk factors for perforation & & \\
Abnormal papilla & 172 & 22.4 \\
Pre-cut & 84 & 10.9 \\
Papillary lesion & 86 & 11.2 \\
Non-dilated common bile duct & 58 & 7.6 \\
Oddi dysfunction & 38 & 4.9 \\
\hline
\end{tabular}

ERCP. Endoscopic retrograde cholangiopancreatography.

(10.9\%) and anticoagulant therapy (7.5\%), for cholangitis were age (42.8\%) and previous ERCP (10.7\%), for perforation were papillary abnormalities (22.4\%) and presence of papillary lesion (11.2\%) (Table 4).

\section{Discussion}

Several factors are involved in the development of post-ERCP complications. These complications, especially PEP, may occur due to patient-related, procedure-related, and endoscopist-related risk factors. The management of the complications and treatment strategies are based on the severity of the compilications (Fig. 1).

The rate of PEP is $3-10 \% \cdot{ }^{[7]}$ Epigastric pain, elevated pancreatic enzyme levels (at least 3 times higher) and unscheduled hospitalization leads the physician to PEP diagnosis. ${ }^{[8]}$ Mild pancreatitis requires 1-3 days of hospitalization and moderate pancreatitis requires 4-10 days of hospitalization. Need for surgical or interventional procedures and hospitalization period over 10 days refers to severe pancreatitis. ${ }^{\left[{ }^{9]}\right.}$ In our study, the incidence of PEP was $3.6 \%$. The risk factors for this particular complication were mostly patient-related. None of our patients devel- 


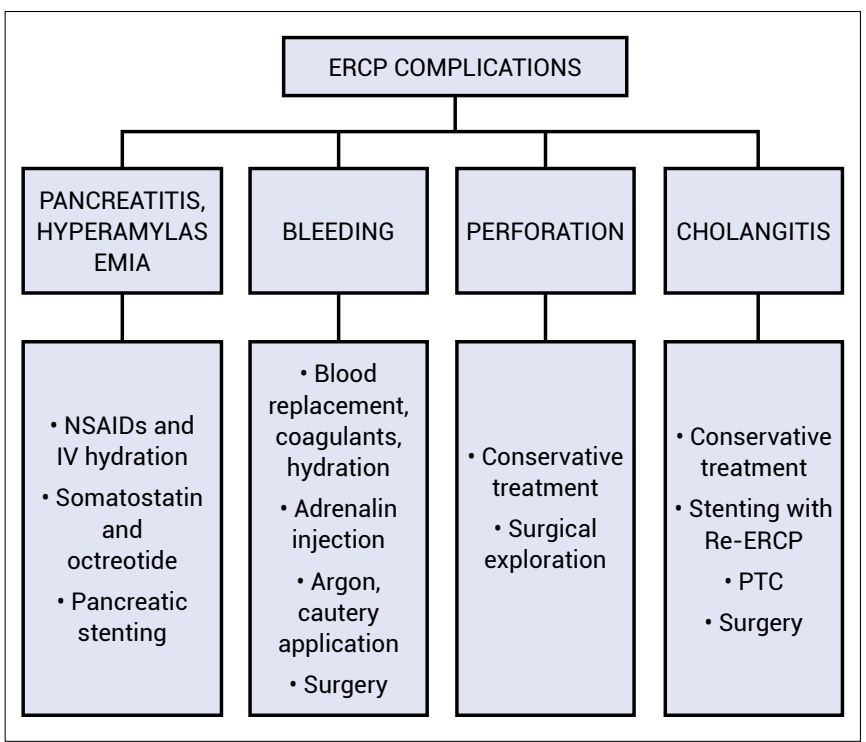

Figure 1. Management of ERCP complications. NSAIDs: Non-steroidal anti-inflammatory drugs; IV: Intravenous; PTC: Percutaneous transhepatic cholangiography.

oped severe pancreatitis. For treatment of the patients with mild and moderate pancreatitis, we ceased oral aliment, administered intravenous hydration, third-generation cephalosporin, non-steroidal anti-inflammatory drugs (NSAID), and all these patients recovered with conservative treatment and hospital stay $<10$ days.

The strategies to reduce PEP risk can be listed as avoiding unnecessary ERCP procedures, limiting cannulation attempts, lowering the amount of contrast agent administered into the pancreatic duct, placing a pancreatic stent as prophylaxis, and using rectal NSAIDs. ${ }^{[3]}$ The treatment strategies in patients hospitalized due to PEP don't have any difference than standard pancreatitis treatment. ${ }^{[10]}$ Basis of the treatment is to cease oral ailment and to administer intravenous hydration, appropriate antibiotics, NSAIDs and when necessary, parenteral nutrition. ${ }^{[3]}$ Cases with severe pancreatitis may require interventional or surgical procedures. ${ }^{[10]}$ In our clinic, mild and moderate PEP rate was $3.6 \%$ and these patients were all treated conservatively.

The incidence of bleeding after endoscopic sphincterotomy (EST) varies from $0.3 \%$ to $9.6 \%{ }^{[11]}$ This complication can be taken under control mostly endoscopically during the procedure or conservatively after the procedure, but with a low rate, additional endoscopic or surgical interventions may be required. ${ }^{[1]]}$ Patient-related risk factors include anticoagulant therapy, coagulopathy (international normalized ratio higher than 1.5), thrombocytopenia (platelet number lower than 50,000/microliter), cholan- gitis, chronic renal failure, and cirrhosis. ${ }^{[12]}$ Procedure-related risk factors include difficult cannulation, papillary abnormalities, impacted stone at the ampulla, performing pre-cut or zipper-cut. ${ }^{[13]}$ The mode and the features of electrocautery device are important. New generation energy devices provide pure cut electrocautery current and this feature makes them safer than old type electrocautery devices and reduces the risk for zipper cut. ${ }^{[13]}$ Even though we have been using an old generation electrocautery device in our endoscopy unit, the zipper cut rate in our series remained at $1 \%$ and no bleeding occurred within these patients.

EST should be done toward 11-13 o'clock. ${ }^{[13]}$ When the papilla can not be placed toward 12 o'clock due to the lack of experience, bleeding may occur after EST. ${ }^{[14]}$ In case of failure to stop the bleeding with endoscopic saline irrigation, diluted adrenalin injection and electrocautery coagulation can be used with a success rate up to $93 \%$. ${ }^{[15]}$ When these efforts fail to stop bleeding, argon plasma coagulation, balloon dilatation of the papilla, biliary metal stent placement, and endoscopic clipping can be used. ${ }^{[16,17]}$ If the bleeding can not be taken under control with all these endoscopic interventions, angioembolisation (pancreaticoduodenal artery or gastroduodenal artery) or surgical treatment options can be life-saving. ${ }^{[16]}$ In our study, bleeding rate after EST was found 2\%. All bleedings were taken under control during the procedure via balloon dilatation of papilla, adrenaline injection, and electrocauterization. Endoscopic reinterventions were required in $20 \%$ of these patients due to rebleeding and they were all treated via endoscopic interventions, no surgical intervention was required.

The most feared post-ERCP complication is perforation. Factors such as manuplation with choledoscope, sphinchterotomy, atypical papillary localization and pre-cut can cause perforation. ${ }^{[18]}$ Post-ERCP perforation rate of experienced endoscopists is $>1 \% \cdot{ }^{[18]}$ Mortality rate of patients with perforation is $7.8-9 \% .{ }^{[19]}$ Perforations mostly occur at the retroperitoneal space therefore the diagnosis can be delayed. Making the diagnosis during or shortly after the procedure may improve the prognosis and reduce the need for surgery. ${ }^{[20]}$ After the procedure, $44 \%$ of patients may present with clinically evident perforation signs. ${ }^{[21]}$ The diagnosis can be made with signs and symptoms such as abdominal pain, tachycardia, peritoneal irritation, leukocytosis, and intraperitoneal free air or contrast extravasation in a contrast-enhanced abdominal tomog- 
raphy scan. The management of all patients with perforation needs to include cessation of oral alimentation, bile decompression via nasogastric tube, administration of wide-spectrum antibiotics, and intravenous hidration (and nutrition, if necessary). If the diagnosis is made during surgery and the site of perforation is duodenal, it needs to be repaired with clips. ${ }^{[21]}$ When the acute abdomen is present and patient's clinical condition is deteriorating, surgical exploration should not be delayed. In our study, perforation occured in $0.6 \%$ of patients and eosophageal laceration occured in one patient. The patient with esophageal laceration was treated with an esophageal stent which was removed after 3 weeks. One of the patients with perforation had pneumothorax and treated with tube thoracostomy. Two of five patients who had perforation required surgical exploration while the other three patients were treated conservatively. No deaths occured among patients with perforation in our series.

Another post-ERCP complication is cholangitis. Factors such as biliary tract obstruction, defective bile transportation, and bacterial translocation take part in the pathogenesis of cholangitis. Biliary stent placement is recommended for patients with insufficient biliary stone extraction in order to prevent cholangitis. ${ }^{[22]}$ Data reveal the incidence of post-ERCP cholangitis as $1-2.4 \%$ and mortality as $0.1 \%$. Medical conservative approach is the first choice of treatment for the patients diagnosed with post-ERCP cholangitis, and this approach provides recovery in most of the patients. ${ }^{[23]}$ Drainage via biliary stent placement (plastic or metal), stent revision, or percutan transhepatic cholangiography is required in the patients who are non-responsive to conservative treatment. ${ }^{[23]}$ If these procedures fail, surgical exploration may be necessary. ${ }^{[24]}$ In our study, the incidence of cholangitis was $1.83 \%$. Among 16 patients who developed cholangitis, mortality occurred in $12.5 \%$. Biliary stents were placed in two patients after they were diagnosed with post-ERCP cholangitis, but these interventions did not help prevent mortality.

\section{Conclusion}

ERCP is an effective procedure for both diagnosis and treatment of hepatopancreaticobiliary system diseases. Due to the reason that ERCP is an invasive procedure, determination of predictable risk factors before the process, and close follow-up during and after the procedure may help reduce complication rates and enhance treatment success.

\section{Disclosures}

Ethichs Committee Approval: The study was approved by the Bursa State Hospital Ethics Committee (date: 21/04/2021, decision no: 2021-7/17).

Peer-review: Externally peer-reviewed.

Conflict of Interest: None declared.

Authorship Contributions: Concept - U.A., A.T., H.M.C.; Design - U.A., Y.D.F.; Supervision - U.A., A.T., M.Ş.; Fundings: G.D., U.E.E., A.T.; Materials - U.E.E., Y.D.F., M.Ş.; Data collection and/or processing - U.A., Y.D.F., D.Y., M.Ş.; Analysis and/ or interpretation - G.D., H.M.C., M.Ş.; Literature search - U.A., H.M.C., U.E.E.; Writing - U.A., A.T., G.D.; Critical review - U.E.E., D.Y., A.T.

\section{References}

1. Szary NM, Al-Kawas FH. Complications of endoscopic retrograde cholangiopancreatography: how to avoid and manage them. Gastroenterol Hepatol (N Y) 2013;9:496-504.

2. Andriulli A, Loperfido S, Napolitano G, Niro G, Valvano MR, Spirito $F$, et al. Incidence rates of post-ERCP complications: a systematic survey of prospective studies. Am J Gastroenterol 2007;102:1781-8. [CrossRef]

3. Tarnasky PR, Kedia P. Endoscopic retrograde cholangiopancreatography complications: Techniques to reduce risk and management strategies. Gastrointest Interv 2017;6:37-53.

4. Barthet $M$, Lesavre $N$, Desjeux A, Gasmi M, Berthezene P, Berdah $S$, et al. Complications of endoscopic sphincterotomy: results from a single tertiary referral center. Endoscopy 2002;34:991-7. [CrossRef]

5. Christensen M, Matzen P, Schulze S, Rosenberg J. Complications of ERCP. a prospective study. Gastrointest Endosc 2004;60:721-31. [CrossRef]

6. Anderson MA, Fisher L, Jain R, Evans JA, Appalaneni V, BenMenachem T, et al. Complications of ERCP. Gastrointest Endosc 2012;75:467-73. [CrossRef]

7. Halttunen J, Meisner S, Aabakken L, Arnelo U, Grönroos J, Hauge $T$, et al. Difficult cannulation as defined by a prospective study of the Scandinavian Association for Digestive Endoscopy (SADE) in 907 ERCPs. Scand J Gastroenterol 2014;49:752-8. [CrossRef]

8. Banks PA, Bollen TL, Dervenis C, Gooszen HG, Johnson CD, Sarr MG, et al. Classification of acute pancreatitis--2012: revision of the Atlanta classification and definitions by international consensus. Gut 2013;62:102-11. [CrossRef]

9. Dumonceau JM, Kapral C, Aabakken L, Papanikolaou IS, Tringali A, Vanbiervliet G, et al. ERCP-related adverse events: European Society of Gastrointestinal Endoscopy (ESGE) guideline. Endoscopy 2020;52:127-49. [CrossRef]

10. Shah AP, Mourad MM, Bramhall SR. Acute pancreatitis: current perspectives on diagnosis and management. J Inflamm Res 2018;11:77-85. [CrossRef] 
11. Cotton PB, Eisen GM, Aabakken L, Baron $T H$, Hutter MM, Jacobson $B C$, et al. A lexicon for endoscopic adverse events: report of an ASGE workshop. Gastrointest Endosc 2010;71:446-54. [CrossRef]

12. ASGE Standards of Practice Committee, Acosta RD, Abraham NS, Chandrasekhara V, Chathadi KV, Early DS, et al. The management of antithrombotic agents for patients undergoing $\mathrm{GI}$ endoscopy. Gastrointest Endosc 2016;83:3-16. [CrossRef]

13. Lin WC, Lin $\mathrm{HH}$, Hung $\mathrm{CY}$, Shih $\mathrm{SC}$, Chu CH. Clinical endoscopic management and outcome of post-endoscopic sphincterotomy bleeding. PloS One 2017;12:e0177449. [CrossRef]

14. Williams, Taylor S, Fairclough P, Hamlyn A, Logan RF, Martin $D$, et al. Risk factors for complication following ERCP; results of a large-scale, prospective multicenter study. Endoscopy 2007;39:793-801. [CrossRef]

15. So YH, Choi YH, Chung JW, Jae HJ, Song SY, Park JH. Selective embolization for post-endoscopic sphincterotomy bleeding: technical aspects and clinical efficacy. Korean $\mathrm{J}$ Radiol 2012;13:73-81. [CrossRef]

16. Maleux G, Bielen J, Laenen A, Heye S, Vaninbroukx J, Laleman W, et al. Embolization of post-biliary sphincterotomy bleeding refractory to medical and endoscopic therapy: technical results, clinical efficacy and predictors of outcome. Eur Radiol 2014;24:2779-86. [CrossRef]

17. Akpınar MY, Torun S, Oztas E, Odemis B. Fully covered metal stents for the treatment of post sphincterotomy bleeding:
Case report. Endoscopy Gastrointestinal 2014;22:44-5.

18. Langerth A, Isaksson B, Karlson BM, Urdzik J, Linder S. ERCPrelated perforations: a population-based study of incidence, mortality, and risk factors. Surg Endosc 2020;34:1939-47. [CrossRef]

19. Park SM. Recent advanced endoscopic management of endoscopic retrograde cholangiopancreatography related duodenal perforations. Clin Endosc 2016;49:376-82. [CrossRef]

20. Kumbhari V, Sinha A, Reddy A, Afghani E, Cotsalas D, Patel YA, et al. Algorithm for the management of ERCP-related perforations. Gastrointest Endosc 2016;83:934-43. [CrossRef]

21. Vezakis A, Fragulidis G, Polydorou A. Endoscopic retrograde cholangiopancreatography- related perforations: diagnosis and management. World $\mathrm{J}$ Gastrointest Endosc 2015;7:1135-41. [CrossRef]

22. Chen $M$, Wang $L$, Wang $Y$, Wei W, Yao YL, Ling TS, et al. Risk factor analysis of post-ERCP cholangitis: a single-center experience. Hepatobiliary Pancreat Dis Int 2018;17:55-8.

23. Saxena P, Singh VK, Lennon AM, Okolo PI, Kalloo AN, Khashab MA. Endoscopic management of acute cholecystitis after metal stent placement in patients with malignant biliary obstruction: a case series. Gastrointest Endosc 2013;78:1758. [CrossRef]

24. Wang P, Li ZS, Liu F, Ren X, Lu NH, Fan ZN, et al. Risk factors for ERCP-related complications: a prospective multicenter study. Am J Gastroenterol 2009;104:31-40. [CrossRef] 